\title{
IMPACTO GERADO EM MICRO E PEQUENAS EMPRESAS EM DECORRÊNCIA DO ISOLAMENTO SOCIAL
}

\section{ARTIGO DE REVISÃO}

SILVA, Patrícia do Carmo Saturnoํ, SANTOS, Wilton Ferraz dos²

SILVA, Patrícia do Carmo Saturno. SANTOS, Wilton Ferraz dos. Impacto gerado em micro e pequenas empresas em decorrência do isolamento social. Revista Científica Multidisciplinar Núcleo do Conhecimento. Ano. 06, Ed. 11, Vol. 11, pp. 157174. Novembro 2021. ISSN: 2448-0959, Link de acesso: https://www.nucleodoconhecimento.com.br/administracao/impacto-gerado, DOI: 10.32749/nucleodoconhecimento.com.br/administracao/impacto-gerado

\section{RESUMO}

Com o surgimento da COVID-19, para evitar o contágio da população, foi estabelecido o distanciamento social e posteriormente o lockdown, o qual se trata de uma medida restritiva de contato. Esta medida objetiva desacelerar o contágio do vírus, gerando assim forte impacto sobre a economia, bem como sobre as organizações empresariais. Neste contexto, o presente artigo, tem como objetivo discutir o impacto da pandemia, através da elaboração de uma revisão bibliográfica de literatura, em empresas de médio e pequeno porte, visando responder à pergunta norteadora: Quais foram os pontos negativos e positivos que as micro e pequenas empresas sofreram durante a pandemia do COVID-19? Trata-se de uma revisão narrativa da literatura, de caráter exploratório e abordagem qualitativa. Para elucidação do estudo foram realizadas buscas na base de dados Google Acadêmico, aplicando como filtro principal, publicações que variavam entre 2020 a 2021. Foram identificados 7.930 artigos mediante a busca em sua totalidade, porém a escolha dos estudos respeitou os critérios de inclusão e exclusão estabelecidos e, após a leitura do título, leitura do

\footnotetext{
${ }^{1}$ Graduação em Administração. ORCID: 0000-0001-6968-4744.

${ }^{2}$ Orientador. Especialista em Gestão tributária. ORCID: 0000-0002-2300-2311.
}

RC: 101880

Disponível em: https://www.nucleodoconhecimento.com.br/administracao/impactogerado 
resumo e total do conteúdo, foram selecionados 32 artigos para composição da presente revisão. Concluiu-se que as micro e pequenas empresas apresentaram altas taxas de encerramento de serviços, algumas foram forçadas a realizar o encerramento de contrato com seus colaboradores, sendo então responsáveis por uma fatia expressiva do desemprego no país neste período, assim como foi evidenciada a dificuldade no acesso aos empréstimos e auxílios do Estado e a baixa adesão a programas de redução, tendo em vista os critérios do programa e a baixa divulgação. Porém, os impactos sofridos por determinadas organizações não envolvem somente fatores negativos, tendo em vista que setores como o delivery, ecommerce, casa e construção, produtos de informática e serviços essenciais demonstraram um crescimento expressivo.

Palavras-chave: Administração, COVID-19, Economia, Micro e pequenas empresas, Pandemia.

\section{INTRODUÇÃO}

Em um período marcado por inúmeros avanços tecnológicos, em um cenário mundial altamente globalizado, o surgimento da COVID-19 provocou forte impacto em todos os setores, em decorrência da ausência do controle de contágio por se tratar de um novo vírus com alto potencial de letalidade (AVENI, 2020).

Para contenção contra contaminação foram adotadas por todo o mundo medidas rigorosas de controle com o objetivo de evitar um possível surto mundial por conta do novo coronavírus, sendo então aplicadas alternativas de restrição a circulação como lockdown, através do bloqueio de abertura dos estabelecimentos comerciais, objetivando a real eficácia do distanciamento social proposto como controle da doença (JUNIOR; SANTA RITA, 2020).

Em consequência das deliberações estabelecidas para controle do COVID-19, inevitavelmente se estabeleceu uma crise a nível mundial que apresenta reflexos humanitários, sociais, econômicos e culturais, onde setores governamentais, 
empresariais e individuais foram expostos a desafios até então não vistos (GARCIEL; NETTO, 2020).

Os impactos gerados pelo COVID-19 ainda não são mensuráveis nem previsíveis, além de que a crise estabelecida apresenta características diferentes das demais crises econômicas da história, ou até mesmo das antigas pandemias. Assim, as projeções realizadas acerca dos impactos gerados pela doença se apresentam equivocadas, devido ao constante avanço da doença (PACCHI, 2020).

No cenário atual, o processo de tomada de decisão realizado pelos agentes econômicos que envolvem empresas, investidores, empregados e consumidores do setor público se relaciona de forma direta com as consequências das ações do setor governamental para contenção da propagação do COVID-19 (CARVALHO; LIMA, 2020).

De acordo com a OMC (Organização Mundial do Comércio), acredita-se que as projeções da expectativa para o comércio mundial em 2021 apresentam incertezas, pois, devido às novas variantes do COVID-19 as perspectivas não são claras, pois em 2020 o PIB mundial apresentou uma queda de $-5,2 \%$, os Estados Unidos $-5,9 \%$, a União Europeia $-7,5 \%$, China -1\% e o Brasil teve uma queda de -8\% (PEREIRA, 2020).

Dados levantados pelo IBGE (Instituto Brasileiro de Geografia e Estatística) demonstram que durante o segundo semestre de 2020 no Brasil, o coronavírus exerceu um impacto negativo sobre $37,5 \%$ das organizações empresariais não financeiras. Esse impacto foi mantido quando comparado ao primeiro semestre, no qual foi visto um percentual em torno de $36 \%$, sendo que setores de varejo, bens de consumo, automotivo, imobiliário, energia elétrica, óleos, gás e petroquímicos, mineração, siderúrgica e setor público exibiram uma redução de atividade e renda durante o ano de 2020 (RAMOS; DELDUQUE; ALVES, 2020).

Sobre níveis mundiais, os governos expuseram medidas com o intuito de amenizar as consequências provocadas pela pandemia. Assim, é notável uma preocupação especial para defender as empresas de pequeno porte que desempenham um papel

RC: 101880

Disponível em: https://www.nucleodoconhecimento.com.br/administracao/impactogerado 
significativo para a oferta de emprego e na continuidade de bens e serviços (DE SALLES, 2020). No Brasil, as empresas de pequeno porte em 2019 eram responsáveis por $54 \%$ dos empregos formalizados no país, além de representarem $27 \%$ do PIB brasileiro (EL KHATIB, 2020).

Em 2020 foram lançados programas de auxílio criado pelo governo e direcionados para pequenas empresas, os quais prometiam oferecer facilidade de obtenção de crédito. As empresas inscritas no programa proposto afirmam que apesar da facilidade prometida, o acesso ao crédito não foi tão simples, pois $64,4 \%$ das organizações de pequeno porte tiveram o auxílio negado; já em relação às empresas de médio porte foram identificadas que 30,5\% dessas não tiveram acesso ao crédito ofertado e 5,1\% das empresas de grande porte não possuíram acesso ao programa de auxílio governamental proposto. Acredita-se que um dos maiores obstáculos para a concessão de crédito consiste nas burocracias e exigências bancárias, além das taxas excessivas de juros (DUARTE et al., 2020).

Uma das alternativas para afastar as consequências lockdown foi a popularização das vendas on-line em boa parte dos segmentos comerciais. Assim, em 2020 o ecommerce ganhou grande notoriedade, tendo em vista que o consumidor recebe 0 produto em casa diminuindo os riscos de contato entre indivíduos e respeitando as medidas de distanciamento (PREMEBIDA, 2020).

No Brasil, as compras online apresentaram crescimento expressivos, e produtos essenciais passaram a ser adquiridos por seus consumidores de forma online (PEREIRA; AZEVEDO, 2020). Desde o início da pandemia, no Brasil, as vendas online de supermercados aumentaram em torno de 16\%, além da conversão média desse setor, a qual aumentou $8,1 \%$. Já as empresas que atuam no segmento de alimentos naturais obtiveram maior visibilidade, além do aumento de $27 \%$ das vendas. As organizações que atuam na área de utensílios doméstico apresentaram um aumento de acesso em seu e-commerce em $33 \%$, além dos tipos de delivery, incluindo sites e aplicativos de entrega que apresentaram uma alta taxa de crescimento (REZENDE; MARCELINO; MYAJI, 2020). 
Diante do exposto o objetivo deste estudo foi analisar através de uma revisão de literatura os principais impactos gerados às micro e pequenas empresas no período pandêmico, por meio do isolamento social, e os reflexos desses fatores na economia. A questão norteadora foi: "Quais foram os pontos negativos e positivos que as micro e pequenas empresas sofreram durante a pandemia do COVID-19?".

\section{METODOLOGIA}

Trata-se de uma revisão narrativa da literatura, de caráter exploratório e abordagem qualitativa. Nesse contexto, o presente estudo utilizou como tema o impacto causado em micro e pequenas empresas em decorrência do isolamento social. A elucidação do presente estudo decorreu durante o período de fevereiro a outubro de 2021.

Partindo desta premissa, foi realizada uma busca na base de dados Google Acadêmico, aplicando como filtro principal publicações com intervalo de publicação entre 2020 a 2021, redigidos em português e inglês, e possibilitando assim a realização de uma abordagem atualizada acerca do tema proposto.

A seleção de artigos partiu do estudo observacional do título e resumo dos artigos que apresentaram os seguintes descritores: Administração; COVID-19; Economia; Micro e pequenas empresas; Pandemia. Como critério de inclusão foram utilizados estudos de caso, estudos descritivos e observacionais, revisões de literaturas simples, sistemáticas e integrativas, livros, capítulos de livros. Os critérios de exclusão foram trabalhos científicos como teses, monografias, resumos de anais e cartas ao autor.

Os artigos utilizados seguiram as estratégias de busca adotadas, mediante a inclusão dos descritores nas bases de dados e a identificação dos artigos com o tema e objetivo do estudo. A realização e triagem de artigos ocorreram através do software Mandeley Desktop® (EUA, 2016). É importante salientar que o processo foi realizado por dois revisores, de forma independente, para que não fossem obtidos resultados divergentes. 
Foram identificados 7.930 artigos mediante a busca em sua totalidade, porém a escolha dos estudos respeitou os critérios de inclusão e exclusão estabelecidos. Após a leitura do título, leitura do resumo e leitura total do conteúdo foram selecionados 32 artigos para composição da presente revisão.

\section{REFERENCIAL TEÓRICO}

\subsection{IMPACTOS DA PANDEMIA E MEDIDAS RESTRITIVAS SOBRE A ECONOMIA E ORGANIZAÇÕES}

O estabelecimento do lockdown em decorrência ao surgimento do COVID-19, com o objetivo de promover o distanciamento social, gerou impacto não somente à saúde pública, mas também às organizações de todos os países afetados pelas medidas de restrição. Os impactos sofridos pelas empresas podem se apresentar de formas diferentes. Estes fatores dependem unicamente do local onde a organização irá operar (CARVALHO; LIMA, 2020).

O possível agravamento do caráter pandêmico pode acarretar a ocorrência de fenômenos que envolvem: interrupção na cadeia de suprimentos da organização, escassez de mão de obra e/ou comprometimento da capacidade de produção, interrupção da procura, entre outros. É importante salientar que por vezes algumas organizações, em menor quantidade, obtêm oportunidades de crescimento, como por exemplo, a queda da concorrência ou efeitos positivos da própria pandemia sobre o mercado em que atua. Assim, para alguns nichos de atuação, os efeitos da pandemia e do lockdown, de modo geral, podem ser positivos. Um exemplo disso são as empresas que comercializam bens considerados essenciais, o que inclui supermercados e farmácias. Existem organizações que utilizam deste período para mudar o foco da empresa. Isso se deve sobre a necessidade em readaptar as necessidades apresentadas pelo mercado (AVENI, 2020).

O Brasil atingiu a marca de 10 milhões de casos do COVID-19 antes mesmo de fazer um ano do surgimento do primeiro caso dessa doença, confirmada em fevereiro de 
2020. A Organização Mundial da Saúde afirmou ao longo do ano de 2020 que a cada três minutos um brasileiro apresentou diagnóstico positivo para o novo coronavírus. Inevitavelmente, os índices não podem ser desvinculados com os dados econômicos apresentados, tendo em vista que o PIB nacional em 2020 caiu cerca de $1,5 \%$ no primeiro trimestre em decorrência da retração de serviços (SALLES, 2020).

Um dos fatores de maior percepção durante e após a crise sanitária com fortes impactos econômicos, será o alto índice de desemprego. Essa problemática surge mediante a incapacidade dos gestores em manterem a sua receita. Desse modo, ocorre o comprometimento de verbas e o administrador é levado a realizar demissões em massa (PREMEBIDA, 2020).

Nesse contexto, torna-se relevante afirmar que as empresas tendem a apresentar equipes reduzidas. Além disso, o processo de automação está sendo solidificado nos mais diversos setores organizacionais, de modo que muitas funções serão consequentemente substituídas (GARCIEL; NETTO, 2020).

O COVID-19 tem sido um grande desafio quanto à estimativa dos impactos exercidos pelo vírus, durante esse período, frente ao ambiente econômico. O cenário atual é de incertezas, tendo em vista que não existem referências comparativas ao cenário atual. Isto torna a atual crise sem precedentes, de modo que a incerteza que paira sobre $o$ ambiente organizacional exige um planejamento a curto, médio e longo prazo. Este planejamento inclui o cenário atual, bem como o período pós-pandemia (RAMOS; DELDUQUE; ALVES, 2020).

Estudos apontam que os impactos da pandemia será um dos maiores já vividos a nível mundial, tendo em vista que medidas de projeção, realizadas em abril de 2020 apresentaram que 50 milhões de pessoas vivem atualmente abaixo da linha de pobreza. Adicionalmente, em junho, a mesma projeção apresentou que mais de 70 milhões de indivíduos sobrevivem abaixo da linha da pobreza (JUNIOR; SANTA RITA, 2020). 


\subsection{SETORES ORGANIZACIONAIS QUE APRESENTARAM BOM DESEMPENHO DURANTE O LOCKDOWN}

O surgimento da pandemia em 2020 afetou diversos setores em decorrência da medida de distanciamento rígido, chamado lockdown. Todos os estados e cidades adotaram em diferentes momentos essa conduta, objetivando reduzir a incidência do COVID-19. Deste modo, foi exigido que o setor comercial também passasse por um processo de readaptação para que a sua atuação não fosse comprometida, mas não negando os impactos que a crise estabelecida pelo isolamento social e lockdown causariam (CALDAS; SILVA SOUZA; BUZOLI, 2020).

Apesar de diversos setores de fato terem tido seus rendimentos comprometidos, segundo Oliveira Souza (2020), áreas como delivery, serviços essenciais, produtos de informática e empreendimentos de casa e construção apresentaram um crescimento exponencial durante esse período.

\subsubsection{DELIVERY}

O serviço de delivery obteve grande ampliação durante a pandemia, tendo em vista o fato de que o consumidor não pode sair de casa. Logo, empresas que não ofertavam esse serviço passaram a disponibilizar a entrega em casa (WEISS, DUARTE, 2020).

Empresas como Ifood $\AA$, Uber Eats $\AA$, Rappi $\AA$, entre outras, apresentaram uma expansão considerável devido à oferta da entrega em casa, o que confere comodidade a compra e redução de riscos pelo fato de o consumidor não ser obrigado a sair de casa para se alimentar (MELO et al., 2020).

A política de delivery já era amplamente conhecida, visto que esse recurso é anterior à pandemia. $\mathrm{O}$ uso expressivo da ferramenta sempre foi característico das empresas do setor alimentício, sendo essas de pequeno, médio ou grande porte. Porém, após a pandemia, o setor essencial expandiu esta ferramenta a qual já fazia uso, além de que

RC: 101880

Disponível em: https://www.nucleodoconhecimento.com.br/administracao/impactogerado 
novos segmentos passaram a aderir a este recurso (BOTELHO; CARDOSO; CANELA, 2020).

O crescimento de empresas especialistas em delivery como Rappi®, Ifood ${ }^{\circledR}$ Uber eats ${ }^{\circledR}$ e 99 taxis $\circledast$ (sendo que as duas últimas não se limitam a delivery de alimentos, mas também de entregas de encomendas), apresentaram um crescimento de $149,1 \%$, $81,9 \%, 91 \%$ e $73 \%$, respectivamente. Os percentuais apresentados evidenciam que o setor de delivery se apresenta como um dos de melhor impacto durante a pandemia (REZENDE; MARCELINO, 2020).

Os aplicativos supracitados também apresentaram maior credenciamento de bares, lanchonetes, restaurantes e empreendedores individuais, os quais optaram a se adequar ao cenário imposto pela crise sanitária. Atualmente, cerca de $72 \%$ das empresas que atuam no ramo alimentício estão cadastradas nos aplicativos de entrega, sendo que as demais já possuem entrega particular (ABRANCHES; LANA, 2020).

\subsubsection{SERVIÇOS ESSENCIAIS}

É de domínio do setor administrativo a influência exercida pelas necessidades e prioridades sobre o processo de decisão de compra. Deste modo, com o surgimento do coronavírus e a mudança do cenário, os objetivos e prioridades de toda a população mundial mudaram. O distanciamento social e o lockdown obrigaram os indivíduos a estarem em casa, surgindo então o home office (trabalhar em casa). Essa nova modalidade, somada a ansiedade de um cenário desconhecido, e associada à necessidade de estar em casa, fez com que a população passasse a consumir uma maior quantidade de itens essenciais, como alimentos, produtos de higiene, limpeza em geral, além dos itens farmacêuticos (SCHNEIDER et al., 2020).

O setor farmacêutico apresentou um crescimento de 13,6\% em 2020, quando equiparado ao ano de 2019. Já o setor mercado varejista demonstrou uma expansão de $16,2 \%$. Um dos fatores que chama a atenção se trata da adoção desses setores à 
oferta de delivery, pois no Brasil os aplicativos de entrega cadastraram uma média superior de 55\% durante 2020, quando comparado a 2019, assim como empresas do varejo alimentício apresentaram um aumento em torno de 52\% em 2020 quando equiparado a 2019 (PELLEGRINI, 2020).

\subsubsection{PRODUTOS DE INFORMÁTICA}

Com o aumento do home office, em decorrência ao distanciamento social, o consumo de produtos de informática apresentou relevante crescimento mediante a necessidade de investir em equipamentos que atendessem a demanda imposta pela rotina de trabalho (MENDONÇA et al., 2020).

Diversos setores organizacionais passaram a investir em recursos de informática para que seus colaboradores pudessem desenvolver as atividades necessárias, mesmo que distantes do ambiente organizacional. Assim, a aquisição de instrumentos e recursos informáticos nesse período se intensificou. Um subproduto apresentou responsabilidade acerca dessa expansão, sendo este o cloud computing, utilizado para armazenamento de dados na nuvem de seguranças e informações, o que oferece garantia acerca da produtividade, além da organização dos dados lançados, tendo em vista os benefícios ofertados pelo recurso em centralizar informações, otimização de espaço, além de minimizar o investimento em hadwares e softwares (ORTEGA; ROCHA, 2020).

\subsubsection{SETOR DE CASA E CONSTRUÇÃO}

O setor de casa e construção concomitantemente como os demais supracitados, apresentou um relevante crescimento durante a pandemia, em decorrência da redução da taxa básica de juros Selic, além do programa governamental Casa Verde e Amarela, que objetiva auxiliar indivíduos que possuem baixa renda à conquista da casa própria. Diante dos fatores expostos, o momento é considerado propício para o investimento em imóveis ou construções civis, fato este que influi diretamente no 
comércio de artigos decorativos e materiais de construção (PEREIRA; AZEVEDO, 2020).

A lógica se baseia na possibilidade de que a compra de imóveis foi intensificada, e ocorrerá o aumento do comércio de artigos decorativos e de materiais de construção. Com o surgimento do coronavírus e da pandemia, a população de modo geral passou a considerar a necessidade de possuir um imóvel próprio, possuindo um espaço que atendesse às demandas diárias. Além disso, este impulso despertou o desejo da realização de reformas ou compra de novos itens de casa e decoração (REZENDE; MARCELINO, 2020).

\subsection{RELEVÂNCIA DO E-COMMERCE NO PERÍODO DE RESTRIÇÃO SOCIAL}

O comércio eletrônico se expandiu de forma evidenciada durante o período da pandemia, que apesar de já conhecido, não apresentava tanta relevância. Acreditase que no Brasil, a região do centro Sul se apresenta em maior destaque quanto à realização de vendas através do e-commerce, com valores superiores a $66 \%$ em 2020, quando comparada ao ano de 2019. A expansão do e-commerce foi um fator de grande surpresa, tornando-se uma nova tendência, sendo considerada uma modalidade aderida de modo irreversível (FREITAS BAUER, 2020).

No Brasil, de forma geral, o ano de 2020 apresentou alta em cerca de $50 \%$ das vendas através do e-commerce quando comparado a 2019, baseado nos dados apresentados pelo comitê de métricas da câmara brasileira de economia digital. Apesar da alta taxa de crescimento anual apresentada pela região centro Sul, no mês de dezembro de 2020 a região Nordeste foi a que mais realizou vendas através do e-commerce, somando um aumento de $78 \%$, seguida pela região Sul com $66 \%$, da região Sudoeste com valores superiores a $48 \%$, Centro-Oeste com $46,99 \%$, e por último a região Norte que possui 39,25\% (SILVA; SILVA; OLIVEIRA, 2020). 
As experiências positivas vividas pelos consumidores através das compras em ecommerce impulsionaram a ferramenta de vendas mediante a quebra de barreiras psicológicas, como por exemplo, o setor de móveis, no qual o consumidor se limitava a realizar a compra apenas presencialmente, em decorrência a necessidade de vislumbrar o objeto de maneira presencial. Porém, devido a não abertura do comércio por um longo período, o consumidor foi obrigado a realizar a sua compra online e obteve sucesso com a mesma. Assim o segmento se consolida no país e demonstra a sua eficiência e benefícios do seu uso diretamente ao consumidor (MACEDO et al., 2020).

\subsection{OS IMPACTOS DA PANDEMIA SOBRE AS MICRO E PEQUENAS EMPRESAS}

As micro e pequenas empresas configuram os empreendimentos que apresentam a maior taxa de mortalidade no Brasil, mediante a realização de pesquisa do serviço brasileiro de apoio às pequenas empresas (SEBRAE). As análises são apresentadas mediante os dados ofertados pela receita federal, os quais demonstram que a interrupção dos serviços de MEP's nos primeiros cinco anos é de 29\% (CALDAS; SILVA SOUZA; BUZOLI, 2020).

Em comparação, às empresas que atuam neste ramo e que permanecem no mercado após o período supracitado, envolvem a capacidade da gestão, a experiência e o conhecimento da área em que se insere (SALLES, 2020). O surgimento do COVID19 gerou inúmeras mudanças no funcionamento das micro e pequenas empresas brasileiras, pois, segundo o Sebrae (2021) cerca de 31\% tiveram o seu funcionamento alterado, porém o fator mais alarmante envolve a interrupção das atividades, de maneira temporária, de mais da metade das microempresas do país (CALDAS; SILVA SOUZA; BUZOLI, 2020).

Apesar das dificuldades enfrentadas com o caráter pandêmico, instalado em decorrência do COVID-19, foi notada a expressiva evolução das micro e pequenas empresas para permanecerem vívidas no mercado. Estudos empíricos evidenciaram 
que em torno de $42 \%$ das empresas, em decorrência do distanciamento social, passaram a funcionar exclusivamente online. Já $41,2 \%$ das empresas aderiram a redução de jornadas, assim como $21 \%$ passaram a exercer suas práticas laborais através do home office (REZENDE; MARCELINO, 2020).

Uma das alternativas adotadas por alguns empresários mediante o surgimento das medidas de distanciamento consistiu na realização de revezamento de horário dos colaboradores. Essa fatia envolve a realização de rodízio entre os colaboradores, medida adotada por um percentual de MEP's, em torno de 15\%. Para lojas de shoppings, foi implementado como medida para continuidade de suas atividades um drive thru. Essa opção foi aderida por cerca de 6\% das micro e pequenas empresas (GONÇALVES et al., 2021). As medidas apresentadas foram tomadas em decorrência da necessidade em obedecer a suspensão estipulada pelo governo do país, fator esse que interferiu em torno de $80 \%$ das MEP's, porém em torno de $20 \%$ optaram interromper a realização de serviços presenciais por conta própria, tendo em vista que estes não se envolviam na lista de atividades dispensáveis (DUARTE et al., 2020).

Os dados apresentados pela Sebrae (2021) evidenciaram que a situação das empresas no que concerne aos ganhos financeiros, demonstraram que a situação, de modo geral, das micro e pequenas empresa já não estavam favoráveis, mesmo antes do estado de calamidade instalada em decorrência do coronavírus. Este fator se justifica mediante a réplica dos empresários que classificaram a situação da empresa como razoável (49\%) e ruins (24\%) (CALDAS; SILVA SOUZA; BUZOLI, 2020).

A fundação Getúlio Vargas, responsável por acompanhar o impacto da pandemia sobre os micro e pequenos negócios, demonstra atualmente uma grande preocupação com o aumento dos custos para produção, tendo em vista que as empresas passaram a não sustentar valores que envolvem aluguel, combustível e nem mesmo insumos (CALDAS; SILVA SOUZA; BUZOLI, 2020).

Apesar dos expressivos avanços em relação a doença do COVID-19, comumente é observado que o faturamento de fato aumentou, porém, a inflação vem se 
intensificando, o que prejudica o processo de retomada planejado. A vacinação foi de fato uma das grandes beneficiárias ao processo de retomada, mas é necessário que sejam realizadas novas medidas de auxílio para as empresas envolvidas, assim como a concessão de empréstimos e crédito a essas organizações que representam boa parte do PIB brasileiro (PEREIRA, 2020).

Os estudos realizados após o relaxamento das medidas restritivas pela SEBRAE demonstram que apesar do fluxo presente no comércio ter sido desautorizado em decorrência da celeridade da vacinação, é evidenciado que $79 \%$ das micro e pequenas empresas ainda apresentam perda no seu faturamento, percentual que permanece o mesmo desde o primeiro trimestre de 2021. Além disso, as análises evidenciaram que as micro e pequenas empresas de forma geral, apresentaram queda em $43 \%$ do seu faturamento quando comparado ao período anterior a pandemia (GONÇALVES et al., 2021).

\subsection{PRINCIPAIS ESTRATÉGIAS PARA RETOMADA DA ECONOMIA A NÍVEL ORGANIZACIONAL DOS MÉDIOS E PEQUENOS EMPREENDEDORES}

O serviço de apoio às micro e pequenas empresas, o Sebrae (2021), afirma que a crise sanitária com impactos econômicos ocasionou um comprometimento jamais visto no último século em relação ao desenvolvimento financeiro dos mais diversos segmentos (CALDAS; SILVA SOUZA; BUZOLI, 2020).

Os dados apresentados pelo SEBRAE apontam que das 65 milhões de empresas classificadas como MEP's, cerca de $30 \%$ podem fechar nos próximos meses em decorrência dos impactos da pandemia, pois devido à ausência de faturamento, os gestores passam a não possuir condições financeiras para continuar mantendo as despesas da empresa. Além disso, o SEBRAE ainda afirma que durante a pandemia $25 \%$ das empresas apresentaram instabilidade e $50 \%$ afirmaram se considerar estáveis (CALDAS; SILVA SOUZA; BUZOLI, 2020).

RC: 101880

Disponível em: https://www.nucleodoconhecimento.com.br/administracao/impactogerado 
Apesar dos fatores relacionados ao impacto da pandemia, acredita-se que o processo de retomada irá acontecer, pois durante a pandemia foi observada a capacidade de adaptação das micro e pequenas empresas com o objetivo de restruturação financeira (GONÇALVES et al., 2021).

Acredita-se que as MEP's devem adotar como alternativa de retomada de forma principal o controle do fluxo de caixa. Assim, faz-se necessária uma autoavaliação das despesas que a empresa possui, com o objetivo de observar a viabilidade de manter o negócio, ou se a melhor opção consiste em encerrar as atividades, ou apenas restringir a atuação da empresa aos níveis necessários (VITÓRIA; MEIRELES, 2020).

Uma alternativa de relevância consiste em negociar prazos, assim como a busca de melhores condições para pagamento de empréstimos, de aluguéis, dentre outras medidas de negociação objetivando maior dilatação a economia (GONÇALVES et al., 2021).

Como alternativa de retomada, devem ser inclusas medidas alternadas que gerem receita, fator que vem se tornando realidade durante todo esse período. É possível observar que os gestores das MPE's estão utilizando a criatividade para gerar soluções inovadoras. Assim, é possível notar a adaptação de pequenas escolas para realização de aulas online, adesão ao sistema de delivery pelos bares e restaurantes, sendo essas algumas medidas para retomada desse segmento empresarial (CALDAS; SILVA SOUZA; BUZOLI, 2020).

\subsection{EXPECTATIVA PARA ECONOMIA NO PERÍODO APÓS PANDEMIA}

Surpreendentemente, os setores de análise econômica afirmam que para o ano de 2021, as perspectivas se apresentam positivas a nível mundial, sendo que os níveis de projeção global envolvem PIB de 5,2\% (PEREIRA, 2020).

RC: 101880

Disponível em: https://www.nucleodoconhecimento.com.br/administracao/impactogerado 
A retomada dos Estados Unidos, bem como o cenário vivido pelo país, apresenta expectativa para um PIB em cerca de $4 \%$ para o fim ano de 2021. O fator pode ser justificado através do pacote fiscal que apresenta valores em torno de $U \$ 900$ bilhões de dólares, sendo considerado um impulso favorável para auxiliar, o que está sendo utilizado no processo de retomada ao consumo (GARCIEL; NETTO, 2020).

A China apresenta que as condutas para contenção da propagação da COVID-19 foram positivas para retomada, tendo em vista que contribuíram para o controle dos gastos econômicos impostos pela crise. Assim, o PIB para o país está em torno de $2 \%$ em decorrência do baixo investimento na própria economia, porém, ainda é uma expectativa positiva (EL KHATIB, 2020).

As previsões do PIB brasileiro para 2021 estão em torno de 4,2\%. Este fator está relacionado a ampla vacinação da população associado a pretensão de alto gasto, além do relaxamento monetário, que podem criar empregos e auxiliar no processo de retomada da economia (DE SALLES, 2020).

No Brasil, o principal fator encarado como impulso econômico, consiste na geração de emprego, sendo então considerada a normalização no mercado de trabalho, um dos fatores principais para a retomada, pois a diminuição da taxa de desemprego consiste na otimização do consumo e do sustento populacional (DUARTE et al., 2020).

\section{DISCUSSÃO}

Segundo Salomé et al. (2021), em sua pesquisa exploratória de abordagem quantitativa, foi avaliado o impacto do COVID-19 sobre a gestão financeira das micro e pequenas empresas, mediante a aplicação de um questionário semiestruturado. Evidenciou-se que a amostra do estudo apresentou crescimento financeiro no período antecedente à pandemia, assim como os pagamentos eram mantidos em dia. Já após o surgimento do COVID-19, as empresas passaram a apresentar dificuldades no cumprimento de seus acordos financeiros. Deste modo, na amostra estudada por 
Salomé et al. (2021), demonstra-se que os impactos exercidos pelo COVID-19 foram negativos sob o prisma financeiro.

Sales; Macêdo (2021) afirmam que a retomada do setor comercial do país depende diretamente do estado, tornando assim possível o reestabelecimento empresarial e a retomada da economia, porém os autores evidenciam sobre a necessidade da realização de um processo de retomada lento, onde se deve aplicar estratégias administrativas e políticas de incentivos válidos e reais para que a gestão dessas organizações possua forças financeiras para se mantiver posicionadas no mercado.

Duarte et al., (2020) apresentam linhas de crédito com o objetivo de promover reflexões em relação as práticas financeiras para a possibilidade do financiamento de MEP's, frente as incertezas provocadas pelo COVID-19. Os autores em seu estudo equiparam o momento de crise atual com os demais choques já vivenciados e reiteram que as propostas apresentadas pelo estado demonstram pouca aderência pelas organizações em decorrência das exigências impostas pelo governo.

Da mesma forma, Duarte et al. (2020) levantam a necessidade de promover a diversificação de possíveis ferramentas de auxílio ofertadas pelo estado com o objetivo de oferecer uma maior variedade de ampliação dos subsídios ao crédito, além da isenção de juros e taxas somada a avaliação criteriosa do perfil organizacional.

Vitória; Meireles (2021) avaliaram através de uma pesquisa bibliográfica, o impacto econômico causado pelo coronavírus, sobre as micro e pequenas empresas, assim como as consequências para a economia de forma geral. Os autores afirmam que as MEP's tiveram, em sua grande maioria, as práticas de serviço interrompidas, algumas de forma temporária, já outras de forma definitiva, em decorrência dos prejuízos financeiros relacionados à crise. Deste modo, Vitória e Meireles (2021) evidenciam o alto número de demissões associadas a interrupção das atividades das micro e pequenas empresas.

Schreiber; Moraes; Stasiak (2021) que avaliaram os impactos do COVID-19 nas micro e pequenas empresas, demonstraram que a crise não foi observada neste setor, mas

RC: 101880

Disponível em: https://www.nucleodoconhecimento.com.br/administracao/impactogerado 
em todas as áreas empresariais. Além disso, foi evidenciado pelos autores que as empresas avaliadas em seu estudo quali-quantitativo demonstraram comprometimento financeiro mediante a redução drástica em seu faturamento. Além disso, metade da amostra total de 21 empresas relatou ter realizado a redução do quadro de funcionários, porém o fato de grande curiosidade evidenciada pelo estudo é que apenas quatro empresas relataram ter utilizado o auxílio de redução ofertado pelo governo brasileiro.

Segundo Silva; Silva; Oliveira (2021), a existência do marketing digital fez com que as divulgações e vendas dos serviços e produtos das pequenas e microempresas atingissem um público maior e consequentemente aumentassem a sua rentabilidade. Essa ampliação do contato do consumidor diretamente com as empresas passou a ser visto como um ponto positivo nesse período pandêmico, visto que as mesmas conseguem ofertar seus produtos neste novo cenário.

Já de acordo com Premebida (2021), o uso do marketing digital deve ser realizado com cuidado, pois as atuações e postagens são analisadas rigorosamente pelos cidadãos, que possuem abertura para opinar positivamente quanto negativamente, moldando a reputação da empresa.

\section{CONSIDERAÇÕES FINAIS}

A elaboração do presente estudo permite concluir que, com o surgimento do coronavírus e a instalação do caráter pandêmico, todos os setores organizacionais sofreram impactos econômicos, financeiros e sociais. É importante salientar que os impactos sofridos por determinadas organizações não envolvem somente fatores negativos, tendo em vista que setores como o delivery, ecommerce, casa e construção, produtos de informática e serviços essenciais demonstraram um crescimento expressivo, porém tais afirmações devem ser acompanhadas, tendo em vista que os impactos dessa crise serão observados pelos próximos 5 anos, em uma média baixa. Deste modo os benefícios ao longo prazo podem ser extirpados. 
Baseando-se sobre a pergunta norteadora do estudo, estabelecida como: "Quais foram os pontos negativos e positivos que as micro e pequenas empresas sofreram durante a pandemia do COVID-19?", é possível afirmar que se evidenciou que o surgimento do coronavírus gerou impactos expressivamente negativos no âmbito financeiros das MEP's, porém algumas delas conseguiram desenvolver alternativas viáveis para a continuidade de seus serviços, o quê de fato foi um desafio, sendo uma das principais alternativas adotadas, o uso dos recursos digitais, além da adoção do delivery e de ferramentas como drive-tru.

É importante salientar também que as micro e pequenas empresas apresentaram altas taxas de encerramento de serviços, assim como as empresas deste setor foram forçadas a realizar o encerramento de contrato de alguns dos seus colaboradores, sendo então responsáveis por uma fatia expressiva do desemprego no país neste período, assim como foi demonstrada a dificuldade no acesso aos empréstimos e auxílios do estado, bem como a baixa adesão aos programas de redução, tendo em vista os critérios do programa e a pouca divulgação.

\section{REFERÊNCIAS}

ABRANCHES, M. V.; LANA, R. M; OLIVEIRA, T. C. Pandemia por SARS-CoV-2. Cad. Saúde Pública, v. 36, n. 4, p. 1-6, 2020.

AVENI, A. Estratégias atuais e futuras para empresas e profissionais na economia da Covid-19. Revista Processus de Políticas Públicas e Desenvolvimento Social, v. 2, n. 3, p. 46-64, 2020.

BARDIN, L. Análise de conteúdo. 3.ed. Lisboa: Edições 70, 2006.

BOTELHO, L. V.; CARDOSO, L. O.; CANELLA, D. S. COVID-19 e ambiente alimentar digital no Brasil: reflexões sobre a influência da pandemia no uso de aplicativos de delivery de comida. Cadernos de Saúde Pública, v. 36, n. 11, p. 1-5, 2020. 
CALDAS, R. C.; SILVA SOUZA, T. R.; BUZOLI, A. C. CRISE NA PANDEMIA: como o empreendedor pode escapar da crise. Ciência \& Tecnologia, v. 12, n. 1, p. 245-249, 2020.

CARVALHO, J. R.; LIMA, M. P. "O comércio não pode parar": discursos e sentidos, em Redenção-PA, durante o lockdown da pandemia de 2020. Espaço e Tempo midiáticos, v. 3, n. 2, p. 11-11, 2020.

COELHO, M. A. F. Pandemia e recuperação de empresas: a crise sob enfoque do micro e pequeno empresário. Revista Brasileira de Direito Empresarial, v. 7, n. 1, p. 1-19, 2021.

DUARTE, R. G. et al. Formação e impacto das linhas de crédito em tempo de pandemia: práticas e reflexões para os pequenos negócios. Gestão E Sociedade, v. 14, n. 39, p. 3707-3715, 2020.

EL KHATIB, A. S. S. Economía versus epidemiologia: uma análise do trade-off entre mercados e vidas em tempos de COVID-19. Contabilidad y Negocios, v. 15, n. 30, p. $62-80,2020$.

FREITAS BAUER, J. R. et al. Influência da pandemia no e-commerce internacional. Revista da Mostra de Iniciação Científica e Extensão, v. 6, n. 1, p. 53-70, 2020.

GARCEL, A.; NETTO, J. L. S. Do "stay home" ao "lockdown" o impacto das medidas de distanciamento no brasil e no mundo. Revista de Teorias da Democracia e Direitos Políticos, v. 6, n. 2, p. 98-118, 2020.

GONÇALVES, M. E. B. et al. Assessoria econômica às micro, pequenas e médias empresas do município de rio pomba durante a pandemia. EXTRAMUROS-Revista de Extensão da Univasf, v. 1, n. 1, p. 54-65, 2021. 
JUNIOR, R. R. F.; SANTA RITA, L. P. Impactos da Covid-19 na Economia: limites, desafios e políticas. Revista Teste, v. 1, n. 7, p. 35-47, 2019.

KRIPKA, R.; SCHELLER, M.; BONOTTO, D. L. Pesquisa Documental: considerações sobre conceitos e características na Pesquisa Qualitativa. CIAIQ2015, v. 2, n.1, p. 243-247, 2015.

MACEDO, V. et al. Oportunidades para se reinventar: experiências de pequenos negócios durante a pandemia. Revista Inteligência Empresarial, v. 42, n.1, p. 1-9, 2020.

MELO, H. D. et al. Produção de materiais de orientação para compras em formato delivery na região de Picos (Piauí) durante a pandemia de COVID-19. Vigilância Sanitária em Debate: Sociedade, Ciência \& Tecnologia, v. 8, n. 3, p. 178-184, 2020.

MENDONÇA, F. D. et al. Região Norte do Brasil e a pandemia de COVID-19: análise socioeconômica e epidemiológica/North region of Brazil and the COVID-19 pandemic: socioeconomic and epidemiologic analysis/Región Norte de Brasil y la pandemia de COVID-19: análisis. Journal Health Npeps, v. 5, n. 1, p. 20-37, 2020.

OLIVEIRA, H. V.; SOUZA, F. S. Do conteúdo programático ao sistema de avaliação: reflexões educacionais em tempos de pandemia (COVID-19). Boletim de Conjuntura (BOCA), v. 2, n. 5, p. 15-24, 2020.

ORTEGA, L. M. R.; ROCHA, V. F. O dia depois de amanhã na realidade e nas mentes - o que esperar da escola pós-pandemia. Pedagogia em Ação, v. 13, n. 1, p. 30214, 2020.

PACCHI, S. The impact of the corona-19 virus on the law of the crisis/l'impatto del virus corona-19 sul diritto della crisi/o impacto do virus corona-19 na lei da crise. Revista Prisma Juridico, v. 16, n. 4, p. 319-347, 2020. 
PELLEGRINI ELIAS, L. Impactos da Covid-19 sobre o setor de comércio no Brasil e em Santa Catarina. Revista NECAT-Revista do Núcleo de Estudos de Economia Catarinense, v. 9, n. 18, p. 59-76, 2020.

PEREIRA, L. B. V. O debate sobre o comércio mundial na e pós pandemia. Revista Conjuntura Econômica, v. 74, n. 7, p. 63-65, 2020.

PEREIRA, L. L.; AZEVEDO, B. F. O Impacto da Pandemia na Construção Civil. Boletim do Gerenciamento, v. 20, n. 20, p. 71-80, 2020.

PIOVESAN, A.; TEMPORINI, E. R. Pesquisa exploratória: procedimento metodológico para o estudo de fatores humanos no campo da saúde pública. Revista de Saúde Pública, v. 29, n. 4, p. 318-325, 1995.

PREMEBIDA, E. A. E-commerce em 2020, um cenário de oportunidades em meio a pandemia. Research, Society and Development, v. 10, n. 2, p.1-7, 2021.

RAMOS, E. M. B.; DELDUQUE, M. C.; ALVES, S. M. C. Dados pessoais sensíveis e a pandemia de coronavírus: divulgar para proteger? Sensitive personal data and the coronavirus pandemic: disclose to protect? Cad. Saúde Pública, v. 34, n. 7, p. 1-4, 2020.

REZENDE, A. A.; MARCELINO, J. A.; MIYAJI, M. A reinvenção das vendas: as estratégias das empresas brasileiras para gerar receitas na pandemia de covid19. Boletim de Conjuntura (BOCA), v. 2, n. 6, p. 53-69, 2020.

SALLES, A. A. O impacto inicial da pandemia de covid-19 no risco da atividade econômica no brasil. Pesquisa Operacional para o Desenvolvimento, v. 13, n.1, p. 1-16, 2021.

SALOMÉ, F. F. S. et al. O impacto da pandemia do COVID-19 na gestão financeira das micro e pequenas empresas do setor varejista de Cláudio-MG. Research, Society and Development, v. 10, n. 6, p. 1-16, 2021. 
SCHNEIDER, S. et al. Os efeitos da pandemia da Covid-19 sobre o agronegócio e a alimentação. Estudos Avançados, v. 34, n. 100, p. 167-188, 2020.

SCHREIBER, D.; MORAES, M. A.; STASIAK, L. O impacto da crise pelo Covid-19 nas micro e pequenas empresas. Revista Vianna Sapiens, v. 12, n. 1, p. 30-30, 2021.

SILVA, I. F.; SILVA, M. S.; OLIVEIRA, R. L. A utilização do marketing digital pelas microempresas de Poá-SP durante a pandemia do COVID-19. Refas-Revista Fatec Zona Sul, v. 7, n. 4, p. 36-52, 2021.

VITÓRIA, M. F. C.; MEIRELES, E. O microempreendedor em tempos de pandemia: uma análise do impacto econômico em cenário de crise. Brazilian Applied Science Review, v. 5, n. 1, p. 313-327, 2021.

WEISS, H. C.; DUARTE, M. S. A semiótica da Uberização em tempos de pandemia: do autogerenciamento subordinado ao breque dos apps. Revista Contraponto, v. 7, n. 3, p.1-12, 2020.

Enviado: Novembro, 2021.

Aprovado: Novembro, 2021. 